Brit. J. industr. Med., 1963, 20, 218.

\title{
SILICOSIS IN WEST COUNTRY GRANITE WORKERS
}

\author{
BY \\ L. W. HALE and G. SHEERS \\ From the West Cornwall Hospitals Group and the Mass Radiography Service \\ of the South Western Regional Hospital Board
}

(RECEIVED FOR PUBLICATION MAY 8, 1962)

The granite industry in Cornwall and Devon is briefly described, especially the production of dust in dressing the stone.

In 1951, 210 granite masons were examined (about $84 \%$ of the total at that time) and $37(17.6 \%)$ showed silicosis. These men were followed up for 10 years. No silicosis was seen in men with less than 15 years' exposure, but after this time the risk increased to 11 out of 14 in those with over 35 years' exposure. Nine deaths occurred, two of which were due to silicosis. Radiological progression was observed in 13 of the 28 survivors. It was not necessarily associated with additional exposure but was related to age. More young men progressed.

In 1961, 132 of the granite masons (about $93 \%$ of the total at that time) were re-examined and nine new cases of silicosis were found to have developed during the 10-year interval. The exposure in the 1961 cases was comparable with that of similar cases in 1951. Thus, the risk has not been much reduced over this period.

Pulmonary tuberculosis occurred in eight of the 37 cases of silicosis in 1951, and between 1951 and 1961 a further five cases were diagnosed, four being from one locality. This was by far the most frequent and disabling complication. Only one case of progressive massive fibrosis was seen.

More extensive use of protective antituberculous chemotherapy is advocated, and also better dust control.

\section{Description of the Industry}

Cornwall and Devon form the south-western extremity of the granite ridge which extends northeast through England into Scotland. The granite in these areas is an acid rock, occurring by volcanic intrusion of the molten magma into the surface slaty material. It is coarse-grained, and consists mainly of felspars, micas, tourmaline, and quartz. The quartz crystallized latest in time and "binds" the rock and gives it its hardness. The quartz content of this granite varies from place to place, between $30 \%$ and $40 \%$ free silica being usual, though figures well above $50 \%$ free silica are quoted, especially near metallic lodes.

The getting and dressing of the granite has been a considerable industry in the area for many centuries. Rising costs and the development of cheaper building materials have greatly limited the demand for prepared granite for building and paving, and the industry has in recent years been largely focused on monumental work.
In 1900 the granite industry in Cornwall and Devon employed about $10,000 \mathrm{men}$; at present the labour force is in the region of 600 . There are three main areas: $(a)$ the Kerrier Highlands, south of Penryn; (b) St. Breward and thereabouts, north of Bodmin; and $(c)$ the western fringe of Dartmoor, east and west of Tavistock. There are a few large works, employing up to 80 men, but many are small concerns of the "family" type and may not employ more than three or four.

The works consist of quarries, concerned with rock-getting, and yards, where the blocks of granite are shaped, smoothed, scribed, and polished.

Quarrying involves the selection of blocks of rock to be got from the quarry face; drilling of shot-holes patterned to secure suitable blocks without excessive shattering; shot-firing, using gelignite, to dislodge the block required; and subsequent further drilling of rows of holes in the block, into which pegs are then driven to fracture the rock along its natural lines of cleavage, so achieving the initial crude shaping of the block, ready for transport to the yard. The drilling 
is done with pneumatically-operated percussion drills, with no water-feed, and no dust-prevention measures are used. There is no tunnelling for the granite and all the quarrying is in open-air conditions. Quarry work is unskilled or semi-skilled.

The "yards" vary from a quite small clearing on the exposed moorland to the type of yard illustrated (Fig. 1), where 20 or 30 sheds are in use. In the yards large blocks are reduced to a smaller size by

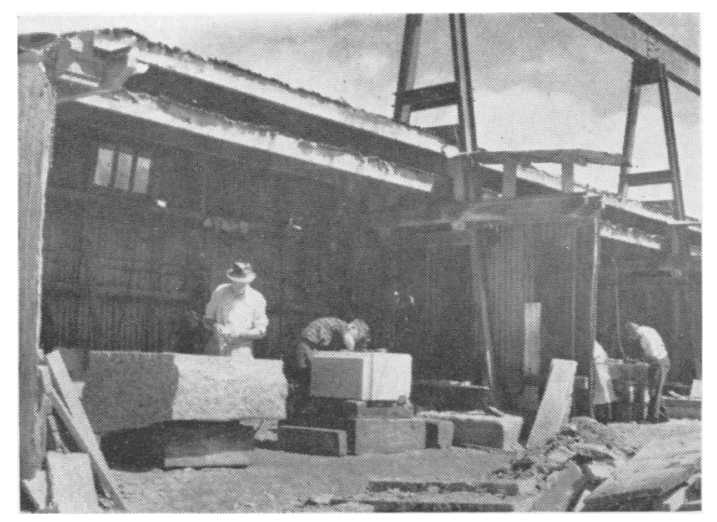

FIG. 1.-Stall, with roof pushed back, and masons working on banker.

sawing with a mechanical saw which works in a spray of water directed on the block. No dust is visible in the process.

Blocks of granite may first be surfaced with the "dunter", a type of heavy mechanical hammer whose striking-face is equipped with rows of chisel-like points. As the striking-face moves to and fro on the surface of the block it removes gross irregularities by fracture. The dunter is the most obvious producer of dust in the processes, but it is used intermittently and is idle for considerable periods, often weeks at a time. The smaller yard may not possess one, all the smoothing being done by hand.

The skilled work of final smoothing, shaping, and scribing is done by tradesmen, known as dressers or banker-masons, the "banker" being the granite slab mounted on wooden joists in the shed where the tradesman works. Banker-masons serve a five-year apprenticeship and, being skilled tradesmen, tend to remain lifelong in the industry.

The sheds, or in a large yard, stalls, are in general of similar pattern and set in a row; the floor dimensions are about $10 \times 12 \mathrm{ft} .(3.2 \times 3.8 \mathrm{~m}$. $)$; the sheds are entirely open-fronted with side walls usually about $1 \mathrm{ft}$. $(0.304 \mathrm{~m}$.) short of the roof, cubicle fashion, the rear walls having a flap-type window about $4 \times 3 \mathrm{ft}$. $(1.37 \times 1.07 \mathrm{~m}$. $)$. The roof has its front half designed like a car sunshine roof, and is pushed back in fine weather. Thus the ventilation is very free, and conditions approximate to those of working in the open air. The banker is set so that the mason has its upper surface at a convenient height to work on it in a standing stooped position, his face being about $1 \mathrm{ft}$. $(0.304 \mathrm{~m}$.) above the surface on which he is working.

The granite mason nowadays uses hand-operated and pneumatically-operated tools about equally, though there may in a few cases be a tendency for a man to specialize to some extent. In general, the smoothing of medium degree may be done by hand, while the finishing of the surface may be done with a small pneumatic chisel, about $1 \mathrm{ft}$. (0.304 m.) long and held rather like a large fountain-pen. Scribing and lettering is almost always done with mechanical tools today.

Pneumatic work on the banker produces a cloud of visible dust about 6 in. $(15 \cdot 24 \mathrm{~cm}$.) in range from the point of the tool, often less. Hand working produces a small spurt of dust of about the same height at each stroke of the hammer (Fig. 2). Much

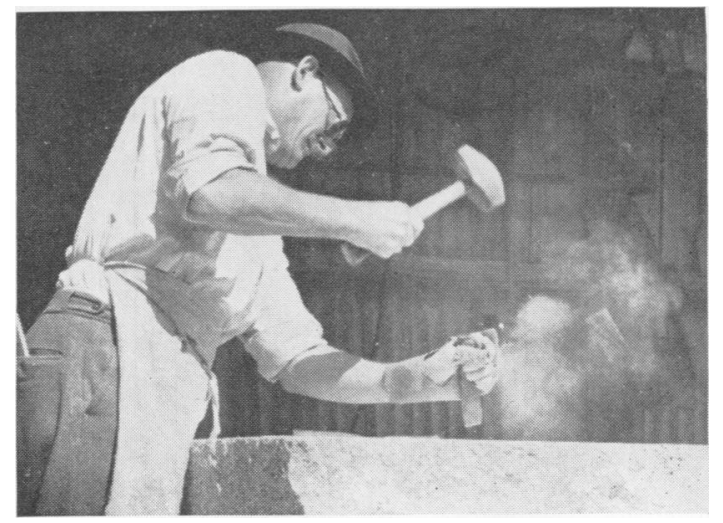

FIG. 2.-Smoothing by hand, showing puff of dust

of the dust found on rafters and shelves in the stalls is obviously coarse and of large particle size; eye injuries due to flying chips are fairly common.

Not infrequently masons experience numbness and tingling in the fingers, and occasionally they have "white fingers" due to the use of vibrating tools. We have not met any case showing necrosis of the skin. Men who use mechanical tools much usually have a "gall" (a cushionlike soft tissue thickening, painless, not callous, and not oedematous) up to the size of half a walnut on the finger, usually the right ringfinger, which they hook round the barrel of the tool when using it.

The finished piece of granite may or may not be polished, according to requirement. Most polishing 
is done mechanically by rubbing the surface with an abrasive disc under a water-spray, but occasionally dry polishing is seen.

Finally, in some of the larger yards there is a building which houses a crusher of the type commonly found in quarries, which produces ballast, chips, gravel, etc. as a by-product from the waste granite. This machine produces much visible air-floated dust, and the rafters in the building are heavily coated with it. Many works do not include a crusher, and the workers with the crusher are unskilled and tend to move more from job to job, within or out of the industry, than do the masons.

\section{Dust-prevention Measures}

Studies of dust concentration or of ventilation have not, as far as we know, been made in the environmental conditions obtaining in this country. They would be difficult to devise, for the working environment is almost "open-air" and subject to variable factors, such as the force and direction of the wind and the amount of rainfall. The distribution of airborne dust arising from the banker may vary according to whether the wind is in the worker's face or from behind, and, if the latter, on the formation of eddies of draught in the lee of his body.

Dust-prevention measures have been difficult to devise and apply, particularly in the work of the masons. They have included jets or sprays of water directed on to the surface being worked, a procedure which is unpopular with the workers; and efforts to extract the dust as it is created, and to remove it by suction pumps to a distance, perhaps under water. This method is objected to on the score that the hood or mouth-piece of the suction apparatus gets in the

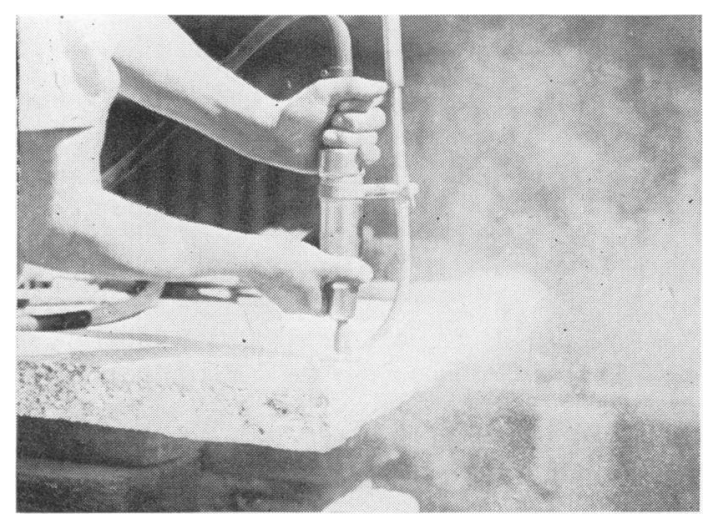

FIg. 3.-Coarse smoothing with a pneumatic tool; note the dust suction tube, working to withdraw dust at the point of the tool, and the cloud of dust notwithstanding. workman's way, and up to the present it has not been completely successful (Fig. 3).

\section{Methods and Materials}

With the co-operation of the Cornish and Devon Granite Masters' Association and the Associated Union of Building Trade Workers, 406 workers in the industry were brought to three centres for clinical and radiographic examination. These were at Longdowns, near Penryn, at De Lank Quarry, near Bodmin, and at Tavistock.

These surveys were carried out between November, 1951, and November, 1952. The total of 406 examinations represents a response of approximately $67 \%$ from all classes of worker in the industry, but the main purpose of the surveys was to examine as many as possible of the granite masons. Of these, there were 250 in the industry in 1951 , and 210 were examined, a response of $84 \%$. Having regard to the number of small, independent firms, totalling approximately 90 , many of which were isolated in remote situations, it was felt that this response was as high as could be expected.

The $\mathbf{2 1 0}$ granite masons formed the subject of the initial investigation. All those in whom silicosis or tuberculosis was suspected were followed up for a period of 10 years. At the end of the 10 years, contraction of the industry had caused a reduction of 40 in the number of employed granite masons. A further 28 had either died or retired, so that the number available for re-examination was no more than 142, of whom 132 were radiographed again between March and September, 1961.

The medical and occupational histories were recorded together with the physical examination of the cardiovascular and respiratory systems, including blood pressure readings and exercise tolerance tests on which an approximate assessment of disability could be based.

An analysis of the ages and lengths of exposure to granite dust of the $\mathbf{2 1 0}$ granite masons is given in column 1 of Table 2. These data relate to 1951 .

The equipment and vehicles of the Mass Radiography Service were made available for the radiographic examinations. The technique complied with the recommendations of the Pneumoconiosis Research Unit of the Medical Research Council (Fletcher, Mann, Davies, Cochrane, Gilson, and Hugh-Jones, 1949). Full-sized standard speed film at a focus-film distance of 60 in. $(1.524 \mathrm{~m}$.) was used with a $400 \mathrm{~mA} x$-ray generator.

Industrial Classification.-Workers were classified into five occupational groups. The term "granite mason" has been applied only to those who had completed their apprenticeship and had a total of not less than five years' experience. Sawyers, polishers, and quarrymen have been classified separately. Apprentices, clerical workers, and drivers have been included under the heading of "others". The numbers examined under each heading are given in Table 1 .

Radiographic Classification.-The Geneva (1958) classification recommended by the International Labour Organisation (I.L.O., 1959) was used in the final categori- 
TABLE 1

NUMBERS OF GRANITE WORKERS EXAMINED IN 1951

\begin{tabular}{l|c|c|c|c}
\hline & Penryn & Bodmin & Tavistock & Total \\
\hline Masons & 114 & 67 & 29 & 210 \\
Sawyers & 6 & 10 & 5 & 21 \\
Polishers & 8 & 34 & 5 & 47 \\
Quarrymen & 39 & 15 & 6 & 60 \\
Others & 22 & 38 & 8 & 68 \\
\hline Total & 189 & 164 & 53 & 406 \\
\hline
\end{tabular}

TABLE 2

ANALYSIS OF AGE AND EXPOSURE OF GRANITE MASONS

\begin{tabular}{|c|c|c|c|}
\hline & $\underset{\text { Examined }}{\text { Total }}$ & \begin{tabular}{|} 
Showing \\
Silicosis \\
at First \\
Examination
\end{tabular} & $\begin{array}{l}\text { Showing } \\
\text { Progression } \\
\text { at Second } \\
\text { Examination }\end{array}$ \\
\hline $\begin{array}{l}\text { Number } \\
\text { Age in } 1951 \text { (yr.) } \\
\text { Average } \\
\text { Range } \\
\text { Groups } \\
20-29 \\
30-39 \\
40-49 \\
50-59 \\
60-69 \\
\text { Exposure in } 1951 \text { (yr.) } \\
\text { Average } \\
\text { Range } \\
\text { Groups } \\
5-15 \\
16-25 \\
26-35 \\
36-45 \\
46+\end{array}$ & $\begin{array}{c}210 \\
40 \\
20-67 \\
30 \\
79 \\
69 \\
17 \\
15 \\
19 \\
5-49 \\
92 \\
67 \\
37 \\
10 \\
4\end{array}$ & $\begin{array}{c}37 \\
50 \\
35-67 \\
-4 \\
18 \\
5 \\
10 \\
30 \\
16-49 \\
-14 \\
12 \\
7 \\
4\end{array}$ & $\begin{array}{c}13 \\
42 \\
35-51 \\
-4 \\
8 \\
1 \\
- \\
22 \\
16-33 \\
- \\
2 \\
-\end{array}$ \\
\hline
\end{tabular}

zation of the radiographs. It was hoped by this means to present the results in a comparable form, but it should not be assumed that this classification necessarily provided a completely satisfactory pattern for all the types of film seen in this investigation.

All films were read on at least two occasions by both of us. In diagnosing silicosis, the demonstration of nodular opacities has been the essential criterion. Added linear opacities were disregarded in making this diagnosis as it was considered that they were open to more than one interpretation.

Difficulty in identifying nodules with certainty arose when they were limited in number and extent and confused by added linear opacities. This difficulty was increased when the changes were limited to the upper zones where infection had to be suspected as a cause of thickened linear and larger nodular opacities. Cases in which there has been any doubt have been rejected, and it is probably for this reason that the number placed in category 1 is low.

Differentiation between category 1 and category 2 has not been a problem, but the distinction between category 2 and category 3 is less precisely defined. Progression has been expressed as a change to a higher category, but the change between the lower and upper limits of category 2 can be striking, and where there has been obvious progression to the borderline between category 2 and category 3 we have tended to use the higher category.
There was only one case of progressive massive fibrosis and this was easily identified at the time of the first examination and placed in category B. The main difficulty encountered in classifying larger opacities was caused by shadows which we considered were probably the result of tuberculous infection. The conventional grouping into "clinically significant" and "inactive" tuberculosis was used in 1951. By "clinically significant" is meant a tuberculous shadow whose presence indicates that the subject should at least be kept under observation (Mann, 1951).

As a result of the 10-year period of observation it has been possible to classify cases of clinically significant tuberculosis more precisely in the follow-up report. In ascribing a tuberculous aetiology to these shadows, the criterion of the positive sputum has not been used because in our experience with this type of case, repeated examinations may be negative despite a definite increase in the extent of the disease as determined radiologically. In none of these cases did we observe coalescence of shadows to form the appearances typical of progressive massive fibrosis. Cases in which a frank break-down of the disease occurred have been described as "clinically active" in order to distinguish them from those showing no more than a slow radiographic advance without cavitation or positive sputum. These have been described as "radiologically active".

\section{Results}

Silicosis.-Evidence of silicosis was found in 37 cases, giving a prevalence rate of $17.6 \%$ in the 210 granite masons in 1951. The radiographic categories of these 37 cases are given in Table 3 together with

TABLE 3

SILICOSIS IN 37 GRANITE MASONS: RADIOGRAPHIC CATEGORY RELATED TO AGE AND EXPOSURE

\begin{tabular}{|c|c|c|c|c|}
\hline & \multicolumn{4}{|c|}{ Category } \\
\hline & 1 & 2 & 3 & 3B \\
\hline $\begin{array}{l}\text { No. of cases } \\
\text { Age }(\mathrm{yr} .)\end{array}$ & 7 & 20 & 9 & 1 \\
\hline $\begin{array}{l}\text { Average } \\
\text { Range }\end{array}$ & $\begin{array}{c}44 \\
37-54\end{array}$ & $\begin{array}{c}48 \\
35-65\end{array}$ & $\begin{array}{c}59 \\
44-67\end{array}$ & 62 \\
\hline $\begin{array}{c}\text { Exposure (yr.) } \\
\text { Average } \\
\text { Range }\end{array}$ & $\underset{16-33}{22}$ & $\begin{array}{l}28 \\
16-46\end{array}$ & $\begin{array}{c}40 \\
27-49\end{array}$ & 43 \\
\hline
\end{tabular}

the average and range of age and exposure to dust in each category in 1951.

In the three geographical groups, the prevalence of silicosis among granite masons at Penryn $(12 \%)$ was only half the rates at Bodmin and at Tavistock (both $24 \%$ ). Some of this difference is accounted for by the higher proportion at Penryn of men under 40 years of age and with an exposure of less than 15 years. Within the comparable age and exposure groups the rates were closer, but there does appear to be evi- 


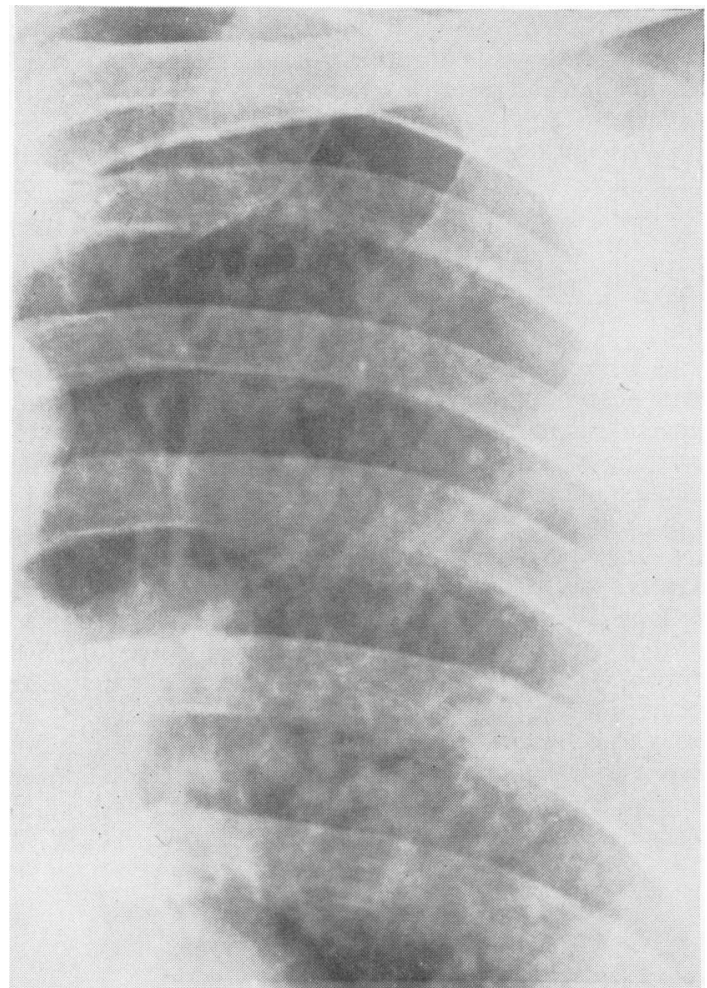

FiG. $4 a$

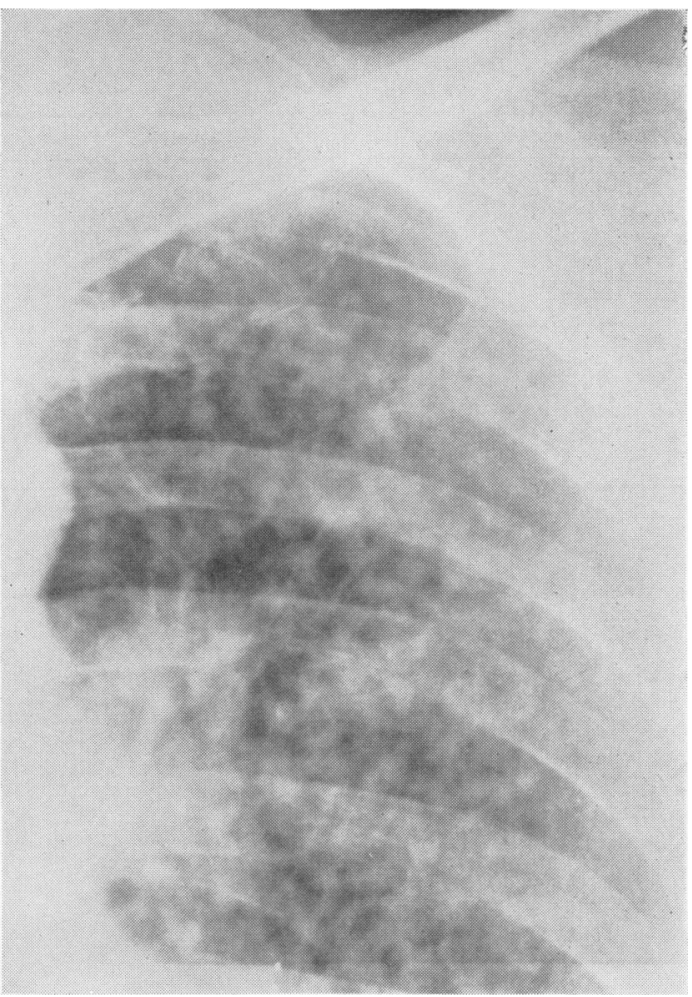

FIG. $4 b$

Fig. 4.-T.C., aged 49: (a) Exposure for 20 years in 1951; (b) progression over 10 years of simple silicosis in the absence of additional exposure.

dence that silicosis developed at a later age and after longer exposure at Penryn.

In 1951, no case of silicosis was found in men with an exposure of 15 years or less; after this time, the prevalence rises progressively, and in the small group with over 46 years' exposure all had silicosis. An analysis of the 37 cases of silicosis by age and exposure is given in column 2 of Table 2.

In quarry workers four cases of pneumoconiosis were found. One of these was attributed to kaolin, the exposure to which had been more than twice as long as the exposure to granite. The other three were cases of silicosis, but one had spent four years underground in a tin mine. The remaining two had been engaged for short periods in surface work at tinmines, but had never worked underground.

By the end of the 10-year period of observation radiological progression had occurred in 13 of the 28 surviving silicotic granite masons. An analysis of the 13 cases by age and exposure is given in column 3 of Table 2. Within the limited group of silicotic granite masons with an exposure of between 16 and 25 years in 1951, 11 progressed whereas only two showed no subsequent evidence of progression.

No relation between progression and additional exposure to dust could be demonstrated. Of the 13 men with progressive silicosis, only five continued to be exposed throughout the full period of 10 years' observation; one was exposed for a further seven years; one for six years; two for four years; one for two years; and three had no additional exposure (Fig. 4).

In the three geographical areas it was noted that the progression rate at Bodmin (nine cases in 16) was substantially higher than at Penryn (two cases in seven) or at Tavistock (two cases in 14).

Changes to a higher radiographic category between the first and second examinations are shown in Table 4. It will be seen that all but one of the six men in category 1 progressed. The single case of progressive massive fibrosis also showed an advance in category from 3B to 3C, but this man is not included in the 28 survivors as he died from carcinoma of the pancreas in 1960. 
TABLE 4

PROGRESSION OF SILICOSIS DURING 10 YEARS' OBSERVATION: RADIOGRAPHIC CATEGORIES OF THE 28 SURVIVORS

\begin{tabular}{l|c|c|c}
\hline & \multicolumn{3}{|c}{ Category } \\
\cline { 2 - 4 } & 1 & 2 & 3 \\
\hline First examination & 6 & 18 & 4 \\
Second examination & 1 & 13 & 14 \\
\hline
\end{tabular}

In the re-examination of 132 granite masons in 1961 a further nine cases of silicosis were diagnosed. Three were placed in category 1 and six in category 2 . Their average age in 1961 was 48, ranging between 38 and 57, and their average exposure was 28 years, ranging between 19 and 37 . All these nine men had continued working at their trade throughout the 10year interval.

Pulmonary Tuberculosis. - In the industry as a whole in 1951, evidence of clinically significant tuberculosis was found in 13 men. Of these, 10 were granite masons, and in eight the infection was associated with silicosis. A further $\mathbf{3 0}$ granite masons showed evidence of inactive tuberculosis, and, of these, 11 had silicosis.

Among the 37 silicotic granite masons, a further five cases of clinically significant tuberculosis were diagnosed during the 10 -year period of observation, giving a total of 13 cases in this small group of men by 1961 . Two of the newly diagnosed cases had been classified as inactive in 1951, and the other three had shown no evidence of the disease at that time. Of these 13 cases, one died in 1961 from a drug-resistant infection, three were clinically active, and the remaining nine showed radiological activity only.

The 12 surviving cases of tuberculosis were evenly distributed between men with progressive silicosis (six cases in 13) and men with stationary silicosis (six cases in 15). Of the five cases newly diagnosed between 1951 and 1961, however, four were associated with progressive silicosis.

Tuberculosis was not associated with any one category of silicosis. Of the 12 surviving cases in 1961 , one was in category 1 , six in category 2 , and five in category 3 . Of the new cases of tuberculosis, three developed at the stage of category 3 silicosis, the other two being in category 2 at the time of diagnosis.

Outside the group of 37 silicotic granite masons four additional cases of clinically significant tuberculosis were diagnosed between 1951 and 1961. One occurred in a non-silicotic mason; one in a quarryman with silicosis; and the remaining two in workers in other sections of the industry.

No tuberculosis was seen in the nine men whose silicosis was first diagnosed in 1961.
TABLE 5

PREVALENCE OF PULMONARY TUBERCULOSIS IN THE GRANITE INDUSTRY IN 1951

\begin{tabular}{|c|c|c|c|}
\hline & No. Examined & $\begin{array}{l}\text { Clinically } \\
\text { Significant }\end{array}$ & Inactive \\
\hline $\begin{array}{l}\text { Granite masons } \\
\text { Other workers }\end{array}$ & $\begin{array}{l}210 \\
196\end{array}$ & $\begin{array}{r}10(4.8 \%) \\
3(1.5 \%)\end{array}$ & $\begin{array}{l}30(14.3 \%) \\
13(6.6 \%)\end{array}$ \\
\hline Total & 406 & $13(3.2 \%)$ & $43(10 \cdot 6 \%)$ \\
\hline
\end{tabular}

The prevalence rates for the whole industry in 1951 showed little difference between the three examination centres. Seven of the nine newly diagnosed cases occurred in the Bodmin area, however, and in consequence the prevalence in this area in 1961 rose above that at Penryn and at Tavistock. The over-all rates together with the figures for the granite masons are summarized in Table 5.

Disability.-Of the 28 surviving silicotic granite masons, 16 remain in full-time employment. Ten of the 16 are carrying on at their trade, although three of them have radiologically active tuberculosis. The other six men who are still at work have left their trade; two of them are in good health; two have radiologically active tuberculosis; one has had clinically active disease and remains partially disabled; and one is partially disabled by emphysema associated with pleural fibrosis and calcified hilar glands.

Of the 12 men who are no longer at work, six are under the age of 65 and are unemployed because of disability. Four of these six have significant tuberculosis, two being clinically active. One man has coronary insufficiency and one is no longer employed because of deafness.

The remaining six men have retired, three being in fair health for their age. Of the other three, one has hypertensive heart disease and two are disabled by dyspnoea attributable to silicosis, in both cases associated with healed tuberculosis and considerable calcification of the hilar glands.

Deaths.-Nine deaths occurred among the 37 granite masons during the 10-year period of observation, but only the two deaths from cor pulmonale could be directly attributed to silicosis. The caủses of death were: carcinoma of the bronchus, 1; carcinoma of the colon, 1; carcinoma of the pancreas, 1; pulmonary tuberculosis, 1 ; cor pulmonale, 2 ; coronary occlusion, 2 ; and aneurysm of the aorta, 1.

In addition to these, one of the quarry workers found to have silicosis died in 1953 from cor pulmonale. 


\section{Discussion}

Previous Investigations.-Sutherland, Bryson, and Keating reported on the occurrence of silicosis amongst granite workers in 1930 . From a total of 494 workers in all parts of Britain they selected 211 for radiography and found evidence of silicosis in $17 \%$. Thirty of the 52 Cornish workers were radiographed and nine showed silicosis. Amongst granite masons, the rate was eight in $23(35 \%)$.

More recently, Mair (1950, unpublished) examined 510 monumental granite workers in Aberdeen. Lengths of exposure are not given for this group as a whole, but most of these men come within our definition of granite mason. He found 56 cases $(11 \%)$ with radiographic evidence of silicosis. Of these, 35 were described as showing either "dust inhalation changes" or "reticulation". The remaining 21 (4\%) were more advanced. These men had a considerably higher average age and length of exposure than the corresponding men in our series. The incidence of tuberculosis unassociated with silicosis was said to be "surprisingly low", but among the 56 men with abnormal radiographs there were two active and four inactive cases.

Comparison is hardly justifiable in view of the degree of selection and the limitations of radiographic technique in 1930, together with the less well-defined radiographic classification in both series.

The Risk of Silicosis.-As regards uncomplicated silicosis, the findings in this investigation have not shown any exceptional features. The over-all prevalence rate of $17.6 \%$ is almost identical with that in the 1930 investigation. Fifteen years' exposure after the completion of apprenticeship appears to be necessary for the production of silicosis, and above this level of exposure the prevalence rises to $31.4 \%$. This also is close to the findings of Sutherland et al. in 1930. The impression that there has been little change in working conditions within the last 20 years is confirmed by the finding that in cases of silicosis newly diagnosed in 1961, the exposure is within the same range as that observed in the same categories in 1951. Men with this length of exposure have reached middle life and are naturally loath to leave a skilled trade, but those who remain would appear to be facing a risk of silicosis which is still as high as one in three.

Although the prevalence of silicosis differed at Penryn and at Bodmin in 1951, the proportion of newly diagnosed cases in 1961 was similar in the two areas (7.7\% at Penryn and $8.7 \%$ at Bodmin), as was the average length of exposure of the new cases (27 years at Penryn and 28 years at Bodmin). The two largest and most mechanized firms are now in the Bodmin area, but these findings do not suggest that trade practices in the two areas can differ materially.

There is a general opinion among the workers that quarrying, sawing, and polishing are jobs with little risk of silicosis. We have met masons who, following a bronchitic illness, have asked for a job in the quarry for a couple of months before returning to work on the banker. This opinion has been borne out as far as sawing and polishing are concerned, but it is evident that quarrying, as at present practised, is not entirely free of risk.

The Delay between Exposure and Radiological Change.-The findings in this investigation indicate a delay of at least 15 years between the initial exposure to dust and the earliest detection of radio-opaque nodules. During the 10-year period of observation an increase in the profusion of nodulation was seen in men who had had no additional exposure. This suggests that a similar delay between exposure and the appearance of additional nodules operates during the second and third decades of dust exposure, and that the occupational history of the 10 years immediately preceding diagnosis may bear little relation to the radiographic changes during the progressive phase of silicosis.

It is clear from the figures that a granite mason, whose silicosis is first diagnosed after an exposure of less than 25 years, may expect the disease to progress at least to the stage of category 2 , and it follows that advice to leave the trade at the time of the first diagnosis is too late in many cases to prevent further pulmonary involvement.

The Relation of Tuberculous Infection and Progressive Silicosis.-In 1951, the prevalence of tuberculosis in masons with silicosis which subsequently progressed was lower than in masons with silicosis which remained stationary.

By 1961 the situation had changed. During the 10year interval there was a higher attack rate of tuberculosis in the group with progressive silicosis and as a result the prevalence in the two groups became almost equal.

These findings suggest that pre-existing tuberculosis does not increase the tendency to progression, but that there may be a relation between recent infection and progressive silicosis.

Further analysis shows that the development of tuberculosis in cases of progressive silicosis was limited to the Bodmin area, and there is other evidence of a higher risk of infection in this locality during the period of observation.

It seems probable, therefore, that the higher attack rate of tuberculosis in masons with progressive sili- 
cosis was due to an increased risk of infection rather than to an increased susceptibility during the progressive phase.

This leaves unexplained the higher rate of progressive silicosis which also occurred at Bodmin in contrast with the other areas. The numbers in this investigation are too small for us to draw firm conclusions, but there does appear to have been an association between recent tuberculous infection and progressive silicosis in this instance.

Pulmonary Tuberculosis.--The problem of progressive massive fibrosis was quite outweighed in this series by the serious extent of reinfection-type tuberculosis. Indeed, this was by far the most disquieting feature of the investigation. The importance of this disease is further stressed by the frequency with which it appears as a cause of disability.

The initial assessment of the activity of tuberculosis is obviously difficult, and the most instructive feature of the 10-year follow-up period proved to be the correction of errors of assessment made in 1951. All but one of the cases originally regarded as of clinical significance subsequently showed signs of either clinical or radiological activity, and three cases initially assessed as inactive later proved to be active. This experience should serve to reinforce the view that all cases in which there is any doubt should be treated as potentially active.

The occurrence of tuberculosis in all categories of simple silicosis necessitates a separate classification of the two diseases, and the simplified convention used by Cochrane, Davies, Chapman, and Rae (1956) in coal-miners' pneumoconiosis cannot therefore be applied to granite workers.

There are many difficulties in applying a more stringent policy to the control of tuberculosis in the industry, though this is clearly needed. Many of the quarries and workshops are situated in remote places. Unemployment rates in these neighbourhoods are relatively high and transfer to other work is resisted. Access to chest clinics is difficult and time consuming. Long-term antituberculous chemotherapy in the earliest stages of the disease and in supposedly quiescent cases cannot be easily supervised on an out-patient basis, and admission to hospital is often declined. Protective chemotherapy is now being used more extensively at the chest clinics in the area, but it is too early to assess its value.

A reduction in the prevalence of tuberculosis in the neighbouring population may be expected to result from continuing work in the preventive field, but it will be many years before men over the age of 35 can hope to feel the benefit. Meanwhile, there is every reason to make still further use of chemotherapy as a preventive as well as a therapeutic measure in cases of silicosis.

In working towards an improvement in the health of the industry, the elimination of preventable infection is obviously of very great importance, but it should not be allowed to overshadow the basic need for better methods of dust control.

We would like to thank all those who helped to make this s.rvey possible and especially Mr. S. Oates for his expert radiography, Miss N. D. Howarth for secretarial assistance, and Miss P. E. Coleman for the photography.

\section{REFERENCES}

Cochrane, A. L., Davies, I., Chapman, P. J., and Rae, S. (1956). Brit. J. industr. Med., 13, 231.

Fletcher, C. M., Mann, K. J., Davies, I., Cochrane, A. L., Gilson, J. C., and Hugh-Jones, P. (1949). J. Fac. Radiol. (Lond.), 1, 40. International Labour Office (1959). Occup. Safety Hlth, 9, 63. International Labour Office (1959).
Mann, K. J. (1951). Thorax, 6, 43.

Sutherland, C. L., Bryson, S., and Keating, N. (1930). Report on the Occurrence of Silicosis amongst Granite Workers. H.M.S.O., London. 